\title{
ANÁLISE DO CONTEXTO DA EDUCAÇÃO BRASILEIRA
}

BASTOS, Manoel de Jesus ${ }^{1}$

BASTOS, Manoel de Jesus. Análise do Contexto da Educação Brasileira. Revista Científica Multidisciplinar Núcleo do Conhecimento. Ano 02, Ed. 01, Vol. 14, pp. 47-54 Janeiro de 2017. ISSN:2448-0959

\section{RESUMO}

Este trabalho tem como objetivo principal, a explicitação da situação da educação brasileira atualmente, seus acertos, equívocos, saltos e retrocessos, pois com uma das mais invejáveis teorias, embeleza e maquia todas as suas etapas, considerando, estatisticamente, dados numéricos, esquecendo-se, no entanto, da efetivação da praticidade para a obtenção dos resultados qualitativos, previstos e garantidos nas leis do próprio sistema. É admissível que a sua acessibilidade tenha sido ampliada nos últimos anos, porém a sua qualidade deixa à desejar, necessitando de cuidados melindrosos para que possam, de fato, efetivar a verdadeira formação do indivíduo. A viabilização de parcerias das famílias com as escolas tornam-se imprescindíveis e continuam sendo os sinalizadores almejados por todos aqueles que fazem educação e acreditam no crescimento positivo num tempo breve. No entanto, é preciso que se mobilize a sociedade para uma reflexão à respeito do processo educacional brasileiro, acionando estratégias posteriores no sentido de atenuar as suas ineficiências.

Palavras-Chave: Educação, Qualidade, Sistema, Ensino, Professores.

\footnotetext{
1 Formado em Normal Superior pela UESPI (Universidade Estadual do Piauí), Pósgraduado em Supervisão Escolar pela Faculdade de Teologia Hokemãh - Fateh e Mestrando em Educação pela Anne Sullivan University.
} 


\section{INTRODUÇÃO}

A educação no Brasil tem sido bastante ampliada nos últimos anos, atendendo de forma homogênea, todas as classes sociais que outrora não usufruía desse precioso direito previsto na Constituição Federal no seu Art. 205 "A educação é direito de todos e dever do estado e da família." A união vem investindo muito no setor, tanto no aperfeiçoamento profissional quanto na parte financeira, em atendimento as leis que regem sobre a área.

No entanto, há, ainda, infinitas lacunas que necessitam, urgentemente, ser corrigidas para a melhoria da qualidade de nossa educação. O sistema educacional tem se flexibilizado demasiadamente nos últimos anos e com imensurável fomentação por estatistas meramente numerológicas. Nos anos iniciais da Educação Básica, o investimento financeiro tende a ser irreversível, ou seja, não há nenhum interesse em repeti-lo naqueles alunos que não conseguiram acompanhar o processo do ensinoaprendizagem, queimando, muitas vezes, etapas importantes e consequentemente prejudicando-os ao longo dos seus estudos.

Sendo assim, é absolutamente correto afirmar que estamos formando muitos analfabetos funcionais, mascarados e longe de consumar o que prevê o artigo supracitado da Constituição Brasileira quando assegura: "Ao concluir o Ensino Médio o indivíduo deve estar preparado para o exercício da cidadania e na sua qualificação para o trabalho." No trem da história educativa do Brasil, falta muito, ainda, para se chegar aos almejos previstos, até mesmo pela carência de faculdades de licenciaturas conceituadas em regiões afastadas dos grandes centros.

Há lados positivos e também problemáticos na educação. Destaco como lado positivo a quase universalização do Ensino Fundamental, elogiável pela quantidade, mas ainda passível na melhoria da qualidade. (SILVA, 2010 - Presid. do C. de Integ. Emp. Escola)

É sabido da necessidade de maiores investimentos aprimorativos nos professores para que se possa fazer uma correção, urgente, de cunho positivo e de uma educação RC: 6659

Disponível em: https://www.nucleodoconhecimento.com.br/educacao/analise-da-educacaobrasileira 
qualitativa, uma vez que a formação real dos educandos depende de professores capacitados e motivados pedagogicamente. As deficiências talvez não sejam exatamente pela falta de verbas, mas de um conjunto de fatores, inclusive a falta de competência e de planejamento para gastá-las.

\section{A SITUAÇÃO DA EDUCAÇÃO BRASILEIRA}

Recentes pesquisas tem mostrado a realidade da educação no Brasil sinalizando a necessidade de melhoramento no que diz respeito a sua qualidade. Acredita-se que os problemas não são oriundos das metas a serem cumpridas, mas na falta de rigorosidade nos resultados pedagógicos. É percebível, com nitidez, a aplicação de planejamentos, porém, didaticamente, ineficazes. Os resultados pretendidos nunca são consumados conforme se planejou. Com as etapas da educação básica fragmentada, o problema tende a persistir ao longo dos estudos, desalicerçando toda a estrutura formativa do indivíduo.

Admite-se, ainda, que o reflexo negativo de uma educação mal sucedida ou sem eficácia, sinaliza uma vasta série de problemas, proporcionando a formação de indivíduos menos cultos e, consequentemente, menos educados. Mesmo sabendo que o Brasil já passou por períodos muito mais críticos na sua história educacional, deve se considerar alguns avanços no que tange a formação de professores, a oferta de materiais didáticos pedagógicos, aspectos de infraestrutura etc., ainda há que melhorar, pois os resultados não estão condizentes com o parecer das políticas públicas governamentais. As escolas públicas não estão conseguindo concretizar, integralmente, as expectativas básicas da aprendizagem como a leitura, a escrita e cálculos.

Se a educação é o instrumento responsável pelo progresso de um país que o faz desenvolver tanto na renda quanto no nível de vida de uma nação, é preciso tê-la como prioridade, diminuindo os discursos e aumentando a didaticidade. Infelizmente os professores tornam-se verdadeiros alvos na culpabilidade da defasagem da educação, sendo cobrados pelo sistema educacional e criticados pela sociedade, 
como se fossem os salvadores da pátria capazes de resolver todos os problemas sociais sozinhos.

Segundo a Organização para Cooperação e Desenvolvimento Econômico - CDE, o Brasil está entre os 76 países no que diz respeito o ranking mundial, ocupando o 60응 lugar, ficando em 1ํ lugar Cingapura seguida da Hong Kong e Coréia do Sul. Isso se deve, talvez, ao número insuficiente de professores formados adequadamente, ministrando aulas na área mais delicada da educação básica. Alguns especialistas apostam que valorizar a profissão investindo na formação dos professores seria a alternativa para concluir resultados educacionais efetivos.

Os dados referentes ao desempenho dos nossos estudantes, em todas as etapas de ensino são decepcionantes. Esse é o reflexo da qualidade da educação que lhes é oferecida. (BERTHA, UERJ. 2014)

Segundo Censo Escolar, em 2013, 21,5\% dos docentes no Brasil, que ministravam aulas nos anos finais do ensino fundamental, não tinham curso superior e 35,4\% não eram habilitados, ou seja, 1/5 (um quinto) dos professores que trabalhavam nessa etapa da educação básica não possuíam graduação. A dificuldade de encontrar professores com formação adequada é, ainda, ocasionada pela baixa atratividade da profissão. A educação brasileira não está entre as melhores do planeta, no entanto, vem superando, paulatinamente, as suas deficiências e, consequentemente, melhorando a sua qualidade. E por saber que ela é considerada o princípio mais importante para o sucesso pessoal e de uma nação, faz-se necessário tê-la como prioridade. Sua ausência possibilita o crescimento desenfreado da pobreza, da marginalidade e da impossibilidade de inserção no mercado de trabalho.

\section{DESVALORIZAÇÃO DOS PROFISSIONAIS EM EDUCAÇÃO NO BRASIL}

Atualmente, professores sentem-se desmotivados à tarefa que Ihes fora concebida, por muitos motivos: antes ele era amado, reconhecido e respeitado por todos os 
alunos e pela sociedade. Essa amabilidade Ihe dava suporte e injetava uma energia imensurável para o desempenho de suas atividades pedagógicas. Infelizmente, houve uma mudança acentuadamente negativa, o respeito que era apregoado pelos alunos esvaiu-se e o amor e reconhecimento dispersaram-se, dando lugar a uma desmotivação no setor.

É admissível afirmar, que a desvalorização da categoria pedagógica provém, de certa forma, da falta de reconhecimento da sociedade que não the oferece o suporte merecido, responsabilizando-os à tarefa educativa, ou melhor, escolarizativa, como se fosse papel exclusivamente seus, quando na verdade é dever de todos, inclusive da família.

De modo que, a desvalorização desses profissionais tem gerado comodismo no que tange à formação adequada e em consequência disso reflete em resultados insatisfatórios. Os cursos de licenciaturas são caminhos que probabilizam uma aprendizagem segura por parte dos alunos, apesar de alguns não atenderem as expectativas da sociedade, deixando muito a desejar.

O próprio professor chega a negar a sua autenticidade achando ser menosprezado dentre outras profissões. Está faltando realismo, ética e compromisso que venham assegurar ampla defesa à profissão docente. A conscientização de que nenhum outro profissional chegará ao ápice almejado, sem antes galgar os bancos escolares, é absolutamente impossível. Como poderia então desvalorizar uma profissão formadora de profissões? Pensando bem, desvalorizar a profissão docente é, ao mesmo tempo, ignorar a construção de uma base sólida formadora em todos os ramos da ciência e menosprezar meios que propiciam o desenvolvimento social. Ou, porventura, poderia haver médicos, advogados, engenheiros..., sem a participação do professor?

\section{OS PROBLEMAS DA EDUCAÇÃO BRASILEIRA}

As Diretrizes Curriculares Nacionais da Educação Básica e o PNE (Plano Nacional de Educação) preveem, como preparação e conclusão do processo formativo dos adolescentes em idades de 15 a 17 anos. No entanto, grande parte dos jovens nessa RC: 6659

Disponível em: https://www.nucleodoconhecimento.com.br/educacao/analise-da-educacaobrasileira 
faixa etária, avançam com frequência. Ainda é absolutamente exorbitante a taxa de evasão escolar aqui no Brasil. Essas evasões acontecem por vários motivos: problemas com professores/as, desânimos, motivos de trabalho, problemas com a família além de outros. É claro que boa parte dessas evasões são tomadas de decisões equivocadas, feitas impulsivamente, sem nenhuma mensuração da gravidade e dos resquícios que estarão no por vir. Nessas circunstâncias, cabe a família e a escola possibilitar subsídios a esses estudantes, mencionando a importância da formação para o exercício da verdadeira cidadania, ou seja, proporcionar as suas integrações no seio escolar.

Há, portanto, uma necessidade urgente de enfrentamento a crise na educação, mais precisamente, no ensino médio. Segundo Maria de Salete Silva, o ensino médio é o maior desafio da educação brasileira, tendo em vista o sobre carregamento de disciplinas a serem ministradas em um tempo tão curto.

Acredita-se que o maior problema da educação brasileira talvez não seja a alegada falta de recursos financeiros, mas a um conjunto de medidas, inclusive planejamento para gastá-los. Dinheiro sem estratégias, metas e ações pedagógicas, jamais resolverá os problemas educacionais.

A sociedade sinaliza que o sistema educacional do país não está preparando jovens com conhecimentos básicos previstos na Constituição Federal. Enquanto os países asiáticos apresentam os melhores resultados na área educacional, o Brasil não consegue apresentar algo satisfatório na mesma.

É observável um outro grande empecilho na educação brasileira: a falta de parcerias das famílias com as escolas. Essas não admitem que a educação dos seus filhos deve partir de si mesmas e terminam sobrecarregando os professores, ou seja, terceirizam responsabilidades que são exclusivamente suas. A necessidade de mudança nesse quadro está gritante e a resolução só aparecerá quando a sociedade, como um todo, convencer-se que essa tão árdua tarefa é muito mais ampla e de interesse de toda a sociedade. 
De modo que a educação no Brasil é extremamente problemática. Os investimentos do governo podem até ser muito, mas aplicados indevidamente. Os professores sofrem com excessivas cargas horárias, trabalhando, muitas vezes, em mais de uma escola, salários baixos, falta de material didático, desconhecimento da tecnologia em sala de aula, carência de coordenadores, supervisores, orientadores pedagógicos, docentes despreparados para os desafios na área, além de outros fatores, que contribuem na má qualidade da educação, e o resultado dessas consequências reflete em uma nação que convive o analfabetismo, elevadas taxas de evasões e baixos rendimentos escolares.

\section{O ENSINO MÉDIO NA EDUCAÇÃO BRASILEIRA}

Todavia, há possibilidades de melhoria na educação brasileira nos últimos dez anos, cuja previsão encontra-se na terceira meta do Novo Plano Nacional de Educação (PNE), quando estabelece as seguintes prioridades: universalizar, até 2016 o atendimento para toda população entre 15 a 17 anos e chegar em 2020 com a taxa líquida de matrículas no Ensino Médio a $85 \%$. Contudo, não basta aumentar a taxa de matrículas sem, no entanto, se preocupar com esforços qualitativos que venham nortear a verdadeira cidadania dos indivíduos. A ineficiência do Ensino Médio no Brasil é realmente preocupante, pois grande parte dos que o concluem não estão preparados para o prosseguimento dos estudos, tampouco o enfrentamento dos desafios que a vida Ihes oferecem ou para exercer a sua cidadania. Adolescente e jovens que deveriam estar cursando em período normal, enveredam-se por cursos supletivos ou os EMITECS (Ensino Médio com Intermediação Tecnológica), ficando assim gigantescas lacunas no processo educativo.

A precariedade do Ensino Médio acentua-se mais ainda nas escolas públicas das zonas rurais nos municípios brasileiros. Geralmente com aprendizado bem abaixo do previsto nas leis da educação, tanto na leitura quanto na escrita e nos cálculos. É um problema oriundo das series iniciais que não sendo corrigido, perdurará ao longo dos estudos. Daí a necessidade de bons profissionais na base da formação educacional e dos conhecimentos. 
Há uma carência muito grande à prática da leitura e da escrita por nossos jovens brasileiros que ainda não se deram conta de suas importâncias e as deixam de pôr em prática no dia a dia. É preciso investir-se mais na base educacional, propiciando meios do gosto e fomentação pela leitura, levando em conta a sua importância para a decolação em todos os setores socioculturais, uma vez que ela é a responsável pelo bom ou mau andamento do processo ensino aprendizagem ao longo dos anos.

É observável que os cursos tecnológicos vem crescendo bastante no Brasil, e por acreditar que eles ajudam na ascensão social, mesmo não sendo de qualidade, muitos dispõem a fazer um sacrifício adicional frequentando-os. Esses cursos, de certa forma, elevam suas habilidades para o bom exercício da profissão e são tratados como prioridades tanto pelo governo quanto pelas instituições representativas das empresas.

Todavia, em meio toda essa gama de deficiências no processo do ensino médio brasileiro, há os que realmente buscam algo para uma melhor formação e que chegam a conquistar os bancos das melhores faculdades públicas, seja através do vestibular ou do Exame Nacional do Ensino Médio (ENEM), isso porque a força de vontade é bem maior do que os obstáculos que descaracterizam o desenvolvimento educacional.

\section{CONSIDERAÇÕES FINAIS}

Refletindo bem a respeito do funcionamento da educação brasileira, atualmente, observa-se que a sua qualidade está aquém das expectativas previstas pela sociedade e garantidas nas leis do próprio sistema. A união tem investido bastante no setor mas os resultados ainda estão longe dos objetivos almejados. Talvez pela falta de um planejamento autêntico e fiscalização rígida nos recursos liberados, uma vez que há, muitos ralos de sangria desnorteando-os do seu destino.

No entanto, não basta a preocupação do governo e das escolas se a própria sociedade acomoda-se deixando de contribuir para a melhoria do seu processo. Enquanto não houver imbuição generalizada nessa tarefa crucial, os problemas $\mathrm{RC}: 6659$

Disponível em: https://www.nucleodoconhecimento.com.br/educacao/analise-da-educacaobrasileira 
tendem a perdurar, incomodando, de certa forma, aqueles que se preocupam e lutam pela abolição do analfabetismo no Brasil. As velhas vendas psicológicas devem ser desmoronadas e a procura incessante pelo iluminismo educacional consistente.

De modo que a busca pela qualidade do ensino brasileiro deve ser contínua e imprescindível. Sair do comodismo e fazer a sua parte é tarefa de todos aqueles que acreditam no resgate do desenvolvimento educacional e efetivação da verdadeira cidadania. A tarefa educativa é da família, do estado e da sociedade que devem investir numa educação qualitativa acreditando num futuro de cidadãos e cidadãs conscientes e responsáveis.

\section{REFERÊNCIAS}

CRISTIANE, Capuchinho do UOL, em São Paulo.

FREITAS, Helena diretora da Anfope (Associação Nacional pela Formação de Profissinais da Educação).

GATTI, Bernadete Pesquisadora do Tema Fundação Carlos Chagas.

OCDE - Organização para Cooperação e Desenvolvimento Econômico e coordenado no Brasil pelo INEP.

UNICEF - Fundo das Nações Unidas para a Infância, no Brasil.

COSTA, Eliane da Bruini, Colaboradora Brasil Escola.

MEC - Ministério da Educação e Cultura.

DIRETRIZES, Curriculares Nacionais da Educação Básica.

PNE - Plano Nacional de Educação.

CONSTITUIÇÃO Federal Brasileira, 1988. 